\title{
An evaluation of the Hollander test by graded vagotomy in the dog
}

\author{
S. NUNDY AND J. H. BARON \\ From the Department of Surgery, Royal Postgraduate Medical School, Hammersmith Hospital, London
}

SUMMARY Hollander's insulin test was evaluated by performing successively partial denervation of the parietal cell area, highly selective, selective, and truncal vagotomy operations on three dogs. The rise in acidity, the timing of the highest rise in acidity, and the rise in acid output were examined.

The mean rise in acidity (m-equiv/l) before vagotomy $(106 \pm \mathrm{SE} 11,120 \pm 23,60 \pm 16)$ did not differ significantly from those obtained after partial denervation $(67 \pm \mathrm{SE} 14,125 \pm 12,45 \pm 12)$. After selective vagotomy, a presumed complete denervation, the rises in acidity were significantly lower $(0 \pm 0 \cdot 1,2 \cdot 5 \pm 4,0 \pm 9)$. The Hollander test, however, was occasionally negative before any nerves had been divided, and was positive in $20 \%$ of tests after presumed complete parietal cell denervation.

The highest rise in acidity before vagotomy most commonly occurred 30 minutes after insulin, and following partial denervation this rise occurred significantly later, most commonly at 60 minutes. After the other operations there was no consistent timing.

The rise in insulin-stimulated acid output after presumed complete denervation provided near complete discrimination between innervated and denervated stomachs, and its repeatability as assessed by the coefficient of variation was significantly better than the repeatability of rise in acidity.

These findings provide support for the contention that the results of the insulin test should be expressed quantitatively in terms of the rise in acid output rather than using Hollander-type criteria of changes in acidity.

Hollander's insulin test is qualitative, not quantitative, and Hollander did not consider that the rise in acidity was any index of the number of intact vagal fibres, that is, there were no so-called 'degrees of vagality' (Jemerin, Hollander, and Weinstein, 1943).

The Hollander test is used extensively in man to assess whether complete denervation of the stomach has been accomplished (Baron and Williams, 1971). In a number of large series the incidence of incomplete denervation (Hollander-positive tests) has ranged between $7 \%$ (Whittaker, Judd, and Stauffer, 1967 ) and $40 \%$ (Jordan and Condon, 1970). Only a third of patients with Hollander-positive tests develop recurrent ulcers and a Hollander-negative test does not confer immunity from the recurrence of ulceration (Clark, Murray, Slessor, and Wyllie, 1964).

It is obviously impossible in man to try and

Correspondence to: Dr J. H. Baron, Department of Surgery, Royal Postgraduate Medical School, Hammersmith Hospital, London W12 OHS.

Received for publication 20 June 1973. validate this test by serial experimental graded vagotomy operations. The insulin test has therefore been assessed by graded vagotomy in the dog. The rise in acidity, the timing of the rise, and the rise in acid output have been examined after insulin stimulation in dogs with intact vagi, deliberately incomplete gastric denervation, and presumed complete denervation.

\section{Material and Methods}

Three female mongrel dogs were used weighing 18, 22 , and $29 \mathrm{~kg}$. After being trained to stand in a Pavlov frame, each dog underwent a series of operations and secretion tests in the following sequence (fig 1): (1) Insertion of a Thomas cannulacreating a chronic gastric fistula; (2) half a highly selective vagotomy (proximal gastric vagotomy). This term refers to the operation known by many names (Wastell, Williams, and Baron, 1973) in which the surgeon aims at denervating the acidsecreting area completely while leaving the nerve 
DIAGRAM OF OPERATIONS

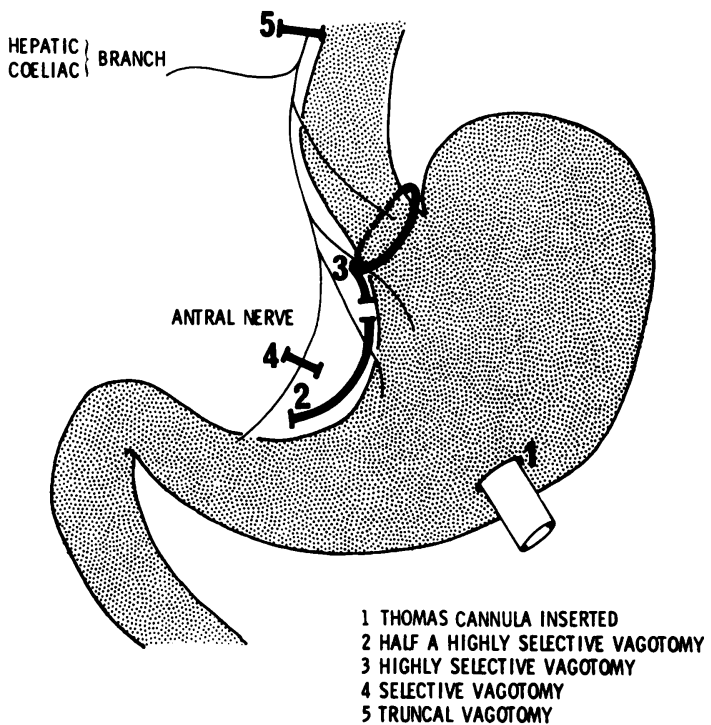

Fig 1 The five operations performed on each dog

supply to the antrum and extragastric organs undisturbed. The acid-secreting area was partly denervated by cutting the nerves in the lesser omentum from the antral border to $1 \mathrm{~cm}$ from the oesophago-gastric junction, preserving the nerve of Latarjet to the antrum. (3) 'Highly selective vagotomy' (proximal gastric vagotomy) - this was completed by dividing the nerves in the remaining lesser omentum and round the oesophagus. (4) Selective vagotomy-after cutting the antral nerves, and (5) truncal vagotomy-by the transthoracic approach. No gastric drainage operations were done at any stage. The dogs remained healthy throughout, ate well, maintained their weight, and showed neither vomiting nor diarrhoea.

Three weeks after each operation the dogs had secretion studies, using insulin (Boots). Each dog received $0.125,0.25,0.5$, and $1.0 \mathrm{u} / \mathrm{kg}$ injected on separate days as a single rapid intravenous bolus. Each test was repeated once, the order of the insulin doses was randomized, and the tests were done at least two days apart.

The gastric juice was collected in 15-minute fractions for half an hour before and two hours after insulin injection. The volume of juice collected was measured to the nearest $0.5 \mathrm{ml}$ and acidity titrated to an endpoint of $\mathrm{pH} \mathrm{7.0} \mathrm{with} \mathrm{an} \mathrm{automatic} \mathrm{titrator}$ (Radiometer, Copenhagen) using $0 \cdot 2 \mathrm{~N} \mathrm{NaOH}$.

The results are expressed as the highest rise in acidity over basal levels (m-equiv/l) and the highest rise in acid output over basal levels (m-equiv/ $30 \mathrm{~min}$ ).

The completeness of vagotomy was confirmed at the end of the experiment by stimulating the intact upper thoracic vagi in the presence of circulating neutral red and examining the gastric mucosa for the secretion of this dye (Pritchard, Griffith, and Harkins, 1968) and also by careful postmortem dissection.

\section{Results}

The results of the insulin tests have been analysed first in terms of the rise in acidity (the Hollander criteria), secondly the timing of the rise, and thirdly in terms of the rise in acid output.

\section{RISE IN ACIDITY}

Figure 2 shows the rise in acidity plotted for all doses of insulin at each stage of the experimentbefore vagotomy, after half a highly selective vagotomy, highly selective vagotomy, selective vagotomy,

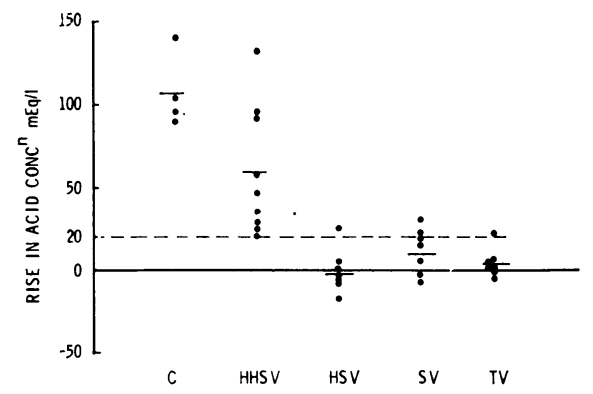

Fig 2 Rise in acidity (dog 1). Each point represents the rise in acidity above basal levels after insulin stimulation at each dose at each stage when the lowest blood sugar level was less than $50 \mathrm{mg} / 100 \mathrm{ml}$.

and truncal vagotomy respectively. Only the results of the experiments in which blood glucose was lowered to below the $50 \mathrm{mg} / 100 \mathrm{ml}$ considered adequate by Hollander have been included.

Before vagotomy the rise in acidity averaged 106 \pm SE11 m-equiv/l; after partial denervation the mean rise was $67 \pm$ SE14 m-equiv/l, an insignificant decrease $(\mathrm{P}>0.05)$. The individual rises were all above $20 \mathrm{~m}$-equiv/l and fulfilled Hollander's criteria of incomplete vagotomy.

After completion of highly selective vagotomy and a presumed complete denervation of the acidsecreting area, each rise in acidity was less than $20 \mathrm{~m}$-equiv/1, all Hollander negative except for one Hollander positive. After selective vagotomy there were two Hollander-positive results and after truncal 
vagotomy one result was Hollander positive. Thus after presumed complete denervation of the parietal cell area, four out of a total of 20 insulin tests were positive.

Dog 2 (fig 3) showed very similar results; before vagotomy and after partial vagotomy all the rises in acidity were over $20 \mathrm{~m}$-equiv/l but after presumed complete denervation again four out of 20 tests remained Hollander-positive.

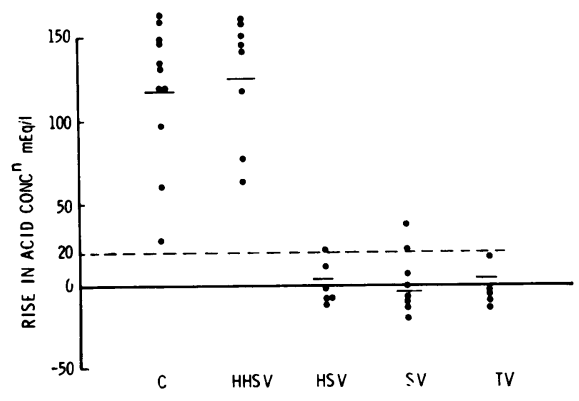

Fig 3 Rise in acidity (dog 2)

In dog 3 (fig 4) even before any vagotomy operation there were three Hollander-negative results and after partial denervation another two negative tests, indicating, according to Hollander, a complete absence of nerve fibres. After proximal gastric vagotomy and subsequent operations four out of 22 tests were Hollander-positive.

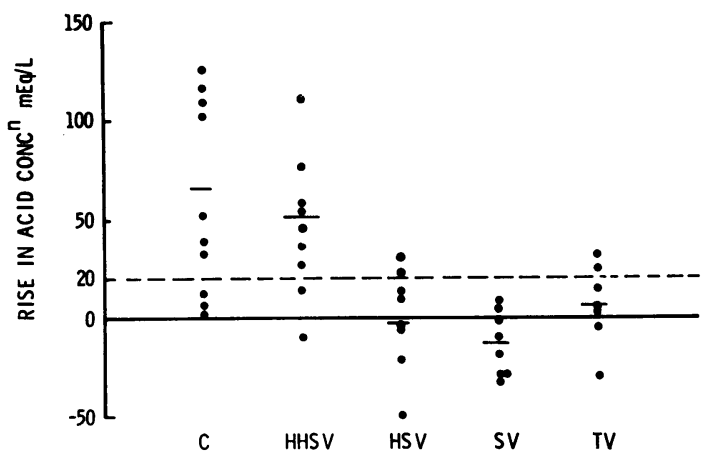

Fig 4 Rise in acidity (dog 3)

If the results on all three dogs are combined, then after presumed complete denervation of the acidsecreting area 12 out of $62(20 \%)$ of insulin tests produced rises in acidity of more than 20 m-equiv/l.

If the vagotomies are presumed to be complete, the Hollander tests indicated incompleteness in $20 \%$. Alternatively if the vagotomies were really incom- plete the Hollander test would indicate an absence of intact nerves and thus be wrong in $80 \%$ of tests.

\section{TIMING OF THE RISE IN ACIDITY}

Figure 5 shows the frequency with which the highest rise in acidity occurred in any particular 15-minute period after stimulation with insulin. Before vagotomy the highest rise occurred almost exclusively 15-45 minutes after insulin. After partial vagotomy the rises in acidity were spread over a wider period, occurring significantly later $(\mathrm{P}<0.001)$, and most commonly between 45 and 60 minutes. After additional operations the timing of the rise in highest peak acidity ranged over the whole 120 -minute period of testing.

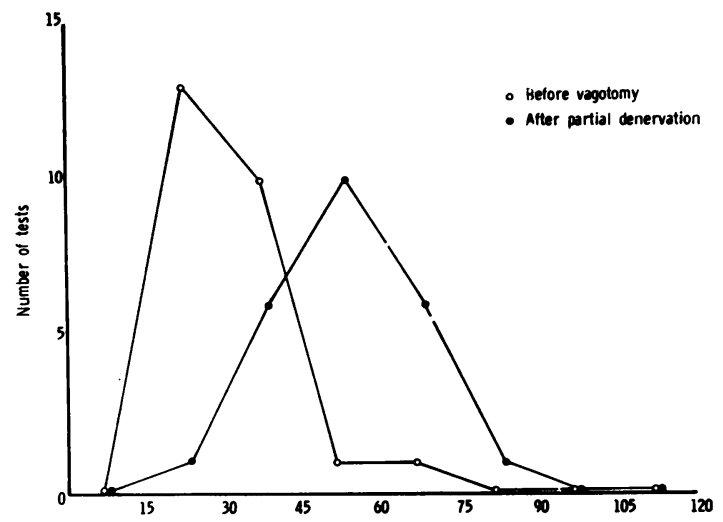

Timing of the highest acid concentration in the 15 minute samples ather insulin

Fig 5 Timing of the highest rise in acidity after insulin. Each point represents the number of tests in which the highest rise in acidity occurred after the given time interval.

RISE IN ACID OUTPUT

Figure 6 shows the individual results of the rise in insulin-stimulated acid output in dog 1 at each stage of the experiment. Before vagotomy the mean rise was $1.7 \pm \mathrm{SE} 0.3 \mathrm{~m}$-equiv/30 min, which was significantly decreased after partial denervation to $0.5 \pm$ $0.15 \mathrm{~m}$-equiv/30 minutes. After highly selective, selective, or truncal vagotomy the mean rises were only $-0.002,0.15$, and $-0.2 \mathrm{~m}$-equiv $/ 30 \mathrm{~min}$ respectively and there was near complete discrimination between the rises of acid output between half a highly selective vagotomy and a highly selective vagotomy, that is, between innervated and denervated stomachs. Very similar results were obtained in dogs 2 and 3 . In dog 2 the rise before vagotomy was $5 \cdot 6 \pm 0 \cdot 9$, after partial denervation $3 \cdot 2 \pm 0 \cdot 9$, and after the three stages of presumed complete denervation there were falls in acid output of $0 \cdot 2 \pm$ 


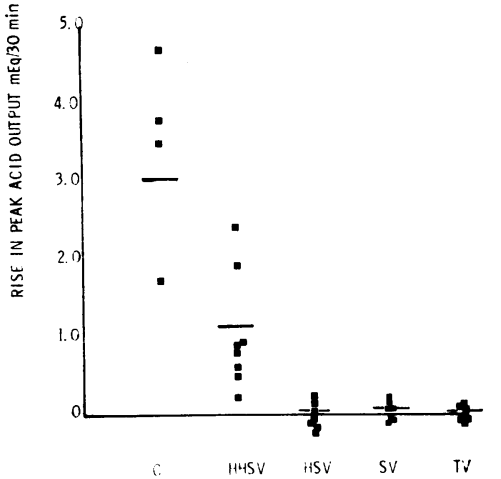

Fig 6 Rise in acid output $(\operatorname{dog} 1)$. Each point represents the rise in acid output above basal levels after insulin stimulation at each dose at each stage.

$0 \cdot 03,0 \cdot 1 \pm 0 \cdot 04$, and $0 \cdot 2 \pm 0 \cdot 1 \mathrm{~m}$-equiv $/ 30$ minutes. In $\operatorname{dog} 3$ the rise before vagotomy was $3 \cdot 1 \pm 0 \cdot 7$, after partial denervation $0 \cdot 8 \pm 0 \cdot 3$, and after the three stages of presumed complete denervation there were falls in acid output of $0 \cdot 1 \pm 0 \cdot 1,0.2 \pm 0 \cdot 1$, and $0 \cdot 2 \pm 0 \cdot 1 \mathrm{~m}$-equiv $/ 30$ minutes.

The repeatability of the acid output measurements as assessed by coefficient of variation (mean CV $211 \pm 50)$ after complete denervation was significantly better $(\mathrm{P}<0.05)$ than the rise in acidity (mean CV $656 \pm 266$ ).

\section{Discussion}

These results suggest that the Hollander test can differentiate innervated from non-innervated parietal cells only approximately. The main drawback of the Hollander test is its qualitative rather than quantitative nature. The test may be negative $(\operatorname{dog} 3)$ even before any vagotomy operation has been done. This confirms Brooke's (1949) finding of seven out of 18 negative responses in unoperated subjects and similar findings by a number of other workers (Gillespie, Gillespie, and Kay, 1969). 'False negative' results may be due to high basal acidity, but this factor was present in only two of five 'false-negative' tests. On the other hand, the Hollander test may be positive after a probably complete denervation of the parietal cells ('false-positive' results). It is interesting to note that after highly selective, selective, and truncal vagotomy, positive Hollander tests were obtained in $21 \%, 19 \%$, and $17 \%$ of the total tests done. This approximates very closely to the mean $21 \%$ incidence (447/2096) of positive Hollander tests after vagotomy that have been reported from different centres (Fawcett, Johnston, and Duthie, 1969) and may cast doubt on the accuracy of the Hollander test for detecting residual vagal innervation.

The delayed timing of the rise in acidity after parietal denervation suggests that the earlier the rise in acidity the more intact vagal fibres remain (Ross and Kay, 1964).

Finally, the facts that the rise in acid output provides better discrimination and is more repeatable than the rise in acidity provide evidence in favour of the increasingly popular contention (Bachrach, 1962) that the results of the insulin test should be expressed quantitatively in terms of the rise in acid output.

This study was supported by grants from the Medical Research Council and the late Dr Tessa Adler. We wish to thank Mr Dennis Humphreys for his technical assistance.

\section{References}

Bachrach, W. H. (1962). Laboratory criteria for the completeness of vagotomy. Amer. J. dig. Dis., 7, 1071-1085.

Baron, J. H., and Williams, J. A. (1971). Use of gastric function tests by British gastroenterologists. Brit. med. J., 1, 196-199.

Brooke, B. N. (1949). The insulin test for vagal section. Lancet, 22, 1167-1170.

Clark, C. G., Murray, J. G., Slessor, I. M., and Wyllie, J. H. (1964), Complete vagotomy and its consequences: followup of 146 patients. Brit. med. J., 2, 900-903.

Fawcett, A. N., Johnston, D., and Duthie, H. L. (1969). Revagotomy for recurrent ulcer after vagotomy and drainage for duodenal ulcer. Brit. J. Surg., 56, 111-116.

Gillespie, G., Gillespie, I. E., and Kay, A. W. (1969). Response to insulin of the intact stomach in patients with duodenal ulcer. Gut, 10, 744-748.

Jemerin, E. E., Hollander, F., and Weinstein, V. A. (1943). A comparison of insulin and food as stimuli for the differentiation of vagal and non-vagal gastric pouches. Gastroenterology, 1, 500512.

Jordan, P. H., Jr., and Condon, R. E. (1970). A prospective evaluation of vagotomy-pyloroplasty and vagotomy-antrectomy for treatment of duodenal ulcer. Ann. Surg., 172, 547-563.

Pritchard, G. R., Griffith, C. A., and Harkins, H. N. (1968). A physiologic demonstration of the anatomic distribution of the vagal system to the stomach. Surg. Gynec. Obstet., 126, 791798.

Ross, B., and Kay, A. W. (1964). The insulin test after vagotomy. Gastroenterology, 46, 379-386.

Wastell, C., Williams, J. A., and Baron, J. H. (1973). Nomenclature of the new vagotomy. Brit. med. J., 1, 482-483.

Whittaker, L. D., Jr., Judd, E. S., and Stauffer, M. H. (1967). Analysis of use of vagotomy with drainage procedure in surgical management of duodenal ulcer. Surg. Gynec. Obstet., 125, 10181026. 